\title{
Caffeine alters oxidative homeostasis in the body of BALB/c mice
}

\author{
Pohanka $\mathrm{M}^{1,2}$ \\ Faculty of Military Health Sciences, University of Defence, Hradec Kralove, Czech Republic. \\ miroslav.pohanka@gmail.com
}

\begin{abstract}
Caffeine is a metabolite from coffee genus and some other plants. It has disparate molecular targets in the body. Beside the major action based on antagonism on adenosine receptor, it is involved in other neurotransmission pathways as well. The complete mechanism of caffeine action remains unrevealed including link to oxidative homeostasis. For the reason, the current paper solves how caffeine influences oxidative homeostasis in BALB/c mouse model. Caffeine was given intramuscularly in doses 1-64 mg/kg and the animals were sacrificed in time intervals from 4 hours up to 3 days. In the experiment, a significant increase of thiobarbituric acid reactive substances (TBARS) levels in the kidney and decrease in the brain indicated up and down regulation of oxidative burden. Ferric reducing antioxidant power (FRAP) level in the kidney appoint at release of low molecular weight antioxidants in the organ. The remaining organs including heart, muscles and liver were intact. In the same way, caspase 3 level was steady and no apoptotic processes were proved (Fig. 3, Ref. 48). Text in PDF www.elis.sk.

Key words: caffeine, oxidative stress, antioxidant, adenosine receptor, Alzheimer disease, neurodegeneration.
\end{abstract}

Caffeine is a secondary metabolite known from some unrelated plants. Coffee plants such as Coffea arabica and C. canephora (1) and tea plants Camellia sinensis $(2,3)$ can be exampled. Formerly, caffeine effect was known from drinking of tea and coffee or consumption of some sweets. Beside coffee and tea, caffeine is added to many drinks, energy drinks, food and drugs $(4,5)$. Caffeine is a drug, which is not legislatively regulated over the world comparing to the other excitation causing substances and despite some adverse effects when caffeine is taken in an excessive amount (6).

In the body, caffeine is targeted to many disparate macromolecular structures. The compound acts as a nonselective adenosine receptor antagonist (7). Though it is believed that the adenosine receptor is the major target, many other enzymes and receptors can meet caffeine. Caffeine can influence neurotransmission through acetylcholine, epinephrine, norepinephrine, serotonin, dopamine and glutamate pathways (8-12).

There is a link between oxidative balance and caffeine. It was proved that caffeine can increase low molecular weight antioxidants and increase enzymes involved in degradation of reactive oxygen species (13). In another experiment, caffeine was found suitable to protect against oxidative stress caused by pentylenetetrazol-induced seizures (3). Caffeine was proved to be effective enough to control inflammatory response in the body during

${ }^{1}$ Faculty of Military Health Sciences, University of Defence, Hradec Kralove, Czech Republic, and ${ }^{2}$ Karel English College in Brno, Brno, Czech Republic

Address for correspondence: M. Pohanka, Faculty of Military Health Sciences, University of Defence, Trebesska 1575, CZ-500 01 Hradec Kralove, Czech Republic.

Acknowledgements: A long-term organization development plan 1011 (Faculty of Military Health Sciences, University of Defense, Czech Republic) is gratefully acknowledged. stress conditions as reported by Tauler and coworkers when they analyzed inflammatory cytokines in humans who underwent run competition (14). It should be emphasized that there is a close link between inflammation and oxidative stress (15). Though the effect of caffeine on oxidative stress was proved in the reported papers, no final conclusion owing to oxidative stress can be done. In this paper, a complex view on the oxidative balance after caffeine intake was done. The paper is aimed at finding of the most effected organs and scale of caffeine impact. Time intervals and lasting of the balance alteration were investigated as well. It is believed that this paper will allow answer how much, where and when the caffeine can alter oxidative balance.

\section{Material and methods}

\section{Experiment on laboratory animals}

The experiment was based on 400 female laboratory mice BALB/c (Velaz, Unetice, Czech Republic). In the beginning of the experiment, the mice weighted $19 \pm 1 \mathrm{~g}$ and they were 8 weeks old. For the whole experiment, the mice were kept in an animal house with temperature adjusted up $22 \pm 2{ }^{\circ} \mathrm{C}$, humidity $50 \pm 10$ $\%$ and light/dark period each 12 hours. The mice had free access to food and water. Prior to the experiment beginning, plan of the project was permitted and then supervised by the ethical committee at Faculty of Military Health Sciences (Hradec Kralove, Czech Republic).

The animals were divided into 20 groups each 20 animals. They received a dose of caffeine 0 (saline) $-1-4-16-64 \mathrm{mg} / \mathrm{kg}$ given intramuscularly into rear limb. Caffeine was solved in saline and applied in amount $100 \mu$. The controls received saline 100 $\mu 1$. The 20 animals per one dose were sacrificed after 4 hours and another 20 animals after one, two and three days. Sacrificing was 
699-703

done under $\mathrm{CO}_{2}$ anesthesia by cutting of jugular vein. The whole liver, kidney, heart, vastus lateralis muscle and brain were collected immediately. The organs were kept at $-80{ }^{\circ} \mathrm{C}$ until assay, which was not later than three weeks after the experiment beginning.

\section{Assay of the markers}

The stored tissues were mechanically homogenized using Ultra-Turrax (IkaWerke, Staufen, Germany) mill device. $100 \mathrm{mg}$ of the tested organ was cut from cortex region and thrown into $1 \mathrm{ml}$ of phosphate buffered saline. The sample was processed by Ultra-Turrax for one minute. The homogenized samples were used immediately for the assays mentioned further.

Ferric Reducing Antioxidant Power (FRAP) is a method/value that respond to overall level of low molecular weight antioxidants $(16,17)$. It was measured using 2,4,6-tris(2-pyridyl)-s-triazine (TPTZ; Sigma-Aldrich) as a chromogenic reagent. A solution containing $10 \mathrm{mmol} / 1 \mathrm{TPTZ}$ and $40 \mathrm{mmol} / 1 \mathrm{HCl}$ was prepared and poured in a ratio $1: 1$ with $20 \mathrm{mmol} / \mathrm{FeCl}_{3}$. An aliquot of the solution sized $5 \mathrm{ml}$ was added into $25 \mathrm{ml}$ of $0.1 \mathrm{~mol} / 1$ acetate buffer $\mathrm{pH} 3.6$ and incubated at $37^{\circ} \mathrm{C}$ for 10 minutes. $30 \mu \mathrm{l}$ of tissue homogenate was given to $200 \mu \mathrm{l}$ of the aforementioned solution, diluted with $770 \mu 1$ of deionized water, incubated for 10 minutes, and spin at $10,000 \times \mathrm{g}$ for another 10 minutes. Absorbance was measured at $593 \mathrm{~nm}$ for the sample comparing to blank, which was saline solution assayed in the same way as the homogenate. FRAP value was calculated using extinction coefficient $\varepsilon=26,000$ $1 / \mathrm{mol} \times \mathrm{cm}$. Interference of caffeine in the FRAP assay was neglected by a separate tests where its level up to $1 \mathrm{mmol} / \mathrm{l}$ was used.

Malondialdehyde is a marker responding to oxidative stress and oxidative damage of lipid membranes (18-20). The malondialdehyde was measured by Thiobarbituric Acid Reactive Substances (TBARS) assay. Firstly, a solution containing $67 \mathrm{mg}$ of thiobarbituric acid (Sigma-Aldrich) in $1 \mathrm{ml}$ of dimethylsulfoxide and $9 \mathrm{ml}$ of deionized water was prepared shortly before use. $200 \mu 1$ of homogenate prepared using the aforementioned protocol was purified from proteins by addition of $400 \mu 1$ of $10 \%$ trichloroacetic acid and incubated for 15 minutes on ice bath. After that, the mixture was centrifuged at $3,000 \times \mathrm{g}$ for 15 minutes. $400 \mu \mathrm{l}$ of supernatant or saline solution (blank) was mixed with another $400 \mu 1$ of the solution containing thiobarbituric acid. In the final step, solution was heated at $99^{\circ} \mathrm{C}$ for 10 minutes. The molar value of TBARS was calculated using extinction coefficient $\varepsilon=156,0001 / \mathrm{mol} \times \mathrm{cm}$. Interference of caffeine in the TBARS assay was neglected by a separate test where its level up to $1 \mathrm{mmol} / \mathrm{l}$ was used.

Caspase 3 was chosen as a marker of apoptotic processes $(19,21)$. The marker was assayed using Caspase 3 Assay kit, Colorimetric (Sigma-Aldrich, Saint Louis, Missouri, USA). The kit was based on spectroscopic determination of caspase 3 enzymatic activity using standard 96 wells microplates and multichannel spectrophotometer. The assay was made in compliance with provided protocol.

\section{Statistics}

Origin 8 Pro (OriginLab Corporation, Northampton, MA, USA) software was used for statistical processing of experimen- tal data. One-way ANOVA with Bonferroni test were used and significance of differences between the experimental groups was tested on probability levels p 0.05 and 0.01 .

\section{Results}

In the animals, no significant behavioral manifestation of exposure to caffeine was observed. On the other hand, behavioral tests were not applied in this experiment so minor alteration in cognitive abilities could pass without notice. Owing to the oxidative stress markers, an unequal effect on the tested organs was found. While TBARS level was significantly increased in the kidney (Fig. 1), the brain level decreased (Fig. 2). No significant alteration in TBARS level was found in samples from liver, heart and vastus

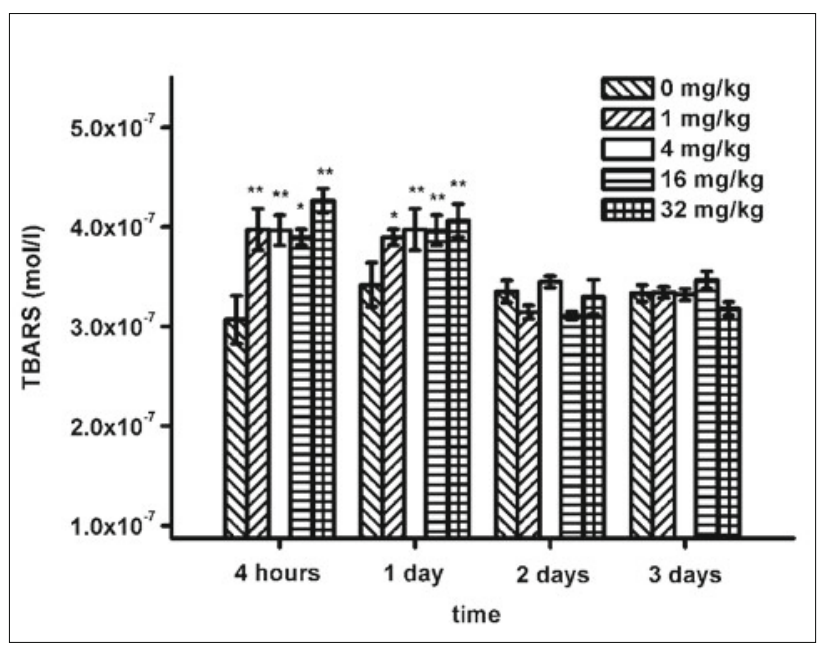

Fig. 1. Thiobarbituric acid reactive substances (TBARS) found in the kidney of mice exposed to caffeine. Dose of caffeine in $\mathrm{mg} / \mathrm{kg}$ is depicted in the Figure. Error bars indicates standard error of mean. * respective ** appoint at significance against the controls at probability level 0.05 respective 0.01 .

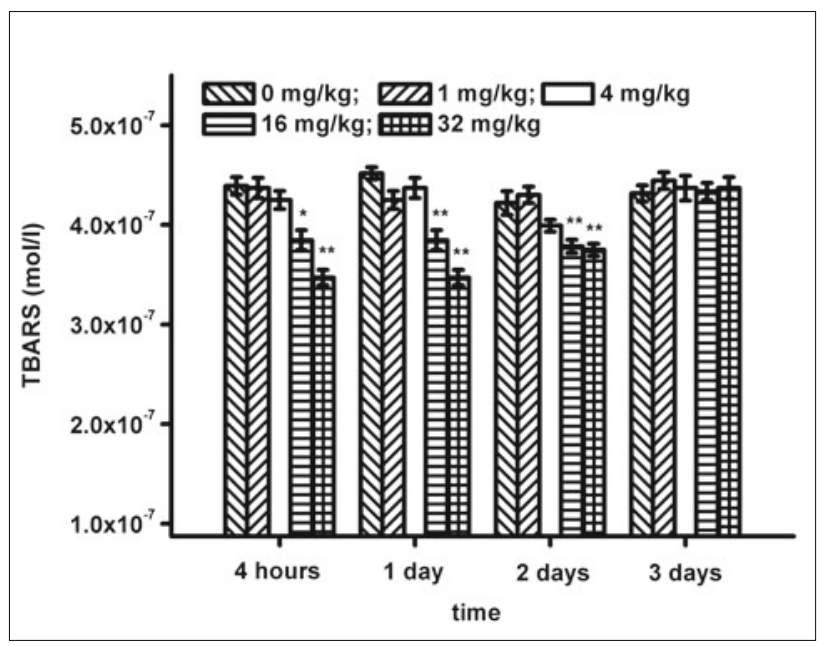

Fig. 2. Thiobarbituric acid reactive substances (TBARS) found in the brain of mice exposed to caffeine. The overall description is same as in Figure 1 case. 


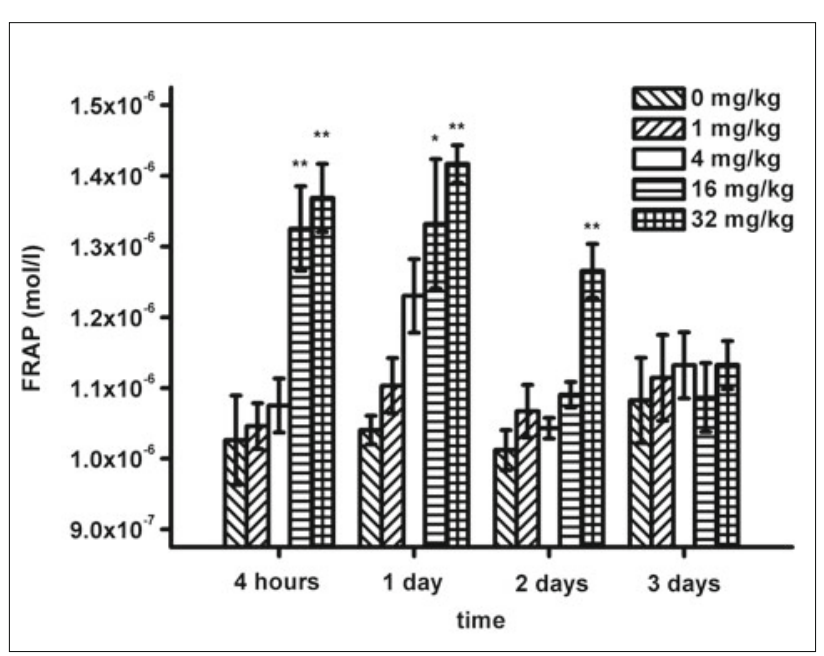

Fig. 3. Ferric reducing antioxidant power (FRAP) found in the kidney of mice exposed to caffeine. The overall description is same as in Figure 1 case.

lateralis muscle (data not shown). In the kidney, caffeine caused elevation of TBAR level in a dose response manner four hours and one day after application of the caffeine. No effect on the TBARS level was proved two and three days after the application. In brain, caffeine caused an opposed effect than in the kidney. The TBARS level was decreased in a dose response manner up to the third day.

FRAP level, a marker of total low molecular weight antioxidants, was altered in the kidney only. The last organs seem to be insensitive to caffeine regarding to FRAP level (data not shown). The FRAP levels in kidneys are depicted in Figure 3. The levels were increased in a dose response manner from the beginning up to the second day after experiment beginning. The effect was significant for the upper doses of caffeine.

Investigation of caspase 3 level in the examined organs did not proved any significant effect of caffeine on the enzyme. The activity of caspase 3 was steady and effect of caffeine on the caspase 3 can be neglected on the account.

\section{Discussion}

Caspase 3 is an enzyme involved in regulation of apoptosis and it can serve as a marker of the apoptotic processes (22-25). No significant effect of caffeine on caspase 3 can be interpreted that caffeine has no ability to initiate apoptosis in the conditions of experiment. In some studies, caffeine was revealed to be able to regulate carcinogenesis progression $(26,27)$. The authors, however, state that some additional work has to be done prior to provide conclusions. They appoint at fact that cell cycle regulation by caffeine is not understood.

Assay of TBARS and FRAP appointed at the unequal effect of caffeine on oxidative balance. While some organs seem to be resistant to caffeine effect, some others are strongly sensitive. An opposed effect was found in kidney and brain regarding to TBARS. It appears that caffeine caused oxidative stress in the kidneys while it could suppress even physiological release of malondialdehyde in the brain. Increased level of FRAP in the kidneys indicates that the body successfully protected itself by accumulation of low molecular weight antioxidants as a consequence of oxidative stress. The significant effect of caffeine on oxidative balance is a little surprising in the animals one and two days after caffeine application. Caffeine easily cross barriers in the body and is eliminated with half time up to 10 hours (28). Beside the elimination, it is metabolized by CYP1A2 $(29,30)$. Here reported result on the improvement of oxidative balance in the brain is in a good compliance with data known in literature where caffeine is reported as a protective factor of neuronal cells (31). The effect on kidney reported here is original. In a study by Inkiewicz-Stepniak and Czarnowski, caffeine was reported as a drug able to ameliorate fluoride initiated oxidative stress in brain, kidney and liver (32). Fact that mice were used here while rats were chosen in the quoted paper can be the explanation of the difference. Moreover, the authors used stress conditions that were not chosen here. Regarding to brain, the results reported here are in a good compliance with the cited paper.

In the current pharmacology, an extensive effort to introduce an effective drug for Alzheimer disease is given by many researchers. Especially, inhibitors of acetylcholinesterase and agonist on N-methy-D-aspartate receptors are available (33-37). Development of effective drugs is limited by fact that the etiology of Alzheimer disease remains unknown and the known therapies ameliorates manifestation only (38-40). In clinical examinations, drinking of 3-5 cups of coffee per a day was proved to be able to decrease risk of Alzheimer disease about $65 \%$ (41). The mechanism of caffeine effect on the Alzheimer disease is not understood. It should be emphasized that coffee contains more components than caffeine only and the components can be responsible for coffee effect as well (42). On the other hand, the majority of scientists contribute the effect to caffeine rather to its metabolites and the other additive compounds presented in coffee (43). The data reported here appointed at reduction of malondialdehyde level in the brain. It means that caffeine altered basal metabolism in the brain in a way to reduce malondialdehyde production. Production of reactive oxygen species, and malondialdehyde is terminal product of membranes damage by the reactive oxygen species, is quite common phenomenon even under physiological conditions $(15,44)$. The lasting exposition to reactive oxygen species is hypothesized as reason of senescence $(45,46)$ and cause of Alzheimer disease initiation (47). A similar cause is hypothesized for Parkinson disease as well (48). Here described effect in the brain can be considered as an explanation of the caffeine related effect on neurodegenerations.

\section{Conclusions}

Caffeine is able to regulate oxidative balance in the body. The effect is unequal to organs in the body. A positive effect in the brain and negative in the kidney was proved. The other organs seem to be resistant. The findings can explain known facts about coffee potency to ameliorate some neurodegenerative processes where central nervous system is a target of pathology. 


\section{References}

1. Magalhaes ST, Fernandes FL, Demuner AJ, Picanco MC, Guedes RN. Leaf alkaloids, phenolics, and coffee resistance to the leaf miner leucoptera coffeella (lepidoptera: Lyonetiidae). J Econ Entomol 2010; 103 (4): 1438-1443.

2. Kravchenko LV, Trusov NV, Aksenov IV, Avreneva LI, Guseva GV, Lashneva NV, Tutelian VA. Effects of green tea extract and its components on antioxidant status and activities of xenobiotic metabolizing enzymes of rats. Vopr Pitan 2011; 80 (2): 9-15.

3. Scoparo CT, de Souza LM, Dartora N, Sassaki GL, Gorin PA, Iacomini M. Analysis of camellia sinensis green and black teas via ultra high performance liquid chromatography assisted by liquid-liquid partition and two-dimensional liquid chromatography (size exclusion $\times$ reversed phase). J Chromatogr A 2012; 1222: 29-37.

4. Guilbeau JR. Health risks of energy drinks: What nurses and consumers need to know. Nurs Womens Health 2012; 16 (5): 423-428.

5. Sepkowitz KA. Energy drinks and caffeine-related adverse effects. JAMA 2013; 309 (3): 243-244.

6. Seifert SM, Seifert SA, Schaechter JL, Bronstein AC, Benson BE, Hershorin ER, Arheart KL, Franco VI, Lipshultz SE. An analysis of energy-drink toxicity in the national poison data system. Clin Toxicol (Phila) 2013; 51 (7): 566-574.

7. Potenza RL, Armida M, Rerrante A, Pezzola A, Matteucci A, Puopolo M, Popoli P. Effects of chronic caffeine intake in a mouse model of amyotrophic lateral sclerosis. J Neurosci Res 2013; 91 (4): 585-592.

8. Szadujkis-Szadurska K, Grzesk G, Szadujkis-Szadurski L, Gajdus M, Matusiak G. Role of acetylcholine and calcium ions in three vascular contraction models: Angiotensin ii, phenylephrine and caffeine. Exp Ther Med 2012; 4 (2): 329-333.

9. Glatter KA, Myers R, Chiamvimonvat N. Recommendations regarding dietary intake and caffeine and alcohol consumption in patients with cardiac arrhythmias: What do you tell your patients to do or not to do? Curr Threat Options Cardiovasc Med 2012; 14 (5): 529-535.

10. Cummings KJ, Commons KG, Trachtenberg FL, Li A, Kinney HC, Nattie EE. Caffeine improves the ability of serotonin-deficient (pet1-/-) mice to survive episodic asphyxia. Pediatr Res 2013; 73 (1): 38-45.

11. Golembiowska K, Dziubina A. The effect of adenosine a(2a) receptor antagonists on hydroxyl radical, dopamine, and glutamate in the striatum of rats with altered function of vmat2. Neurotox Res 2012; 22 (2): 150-157.

12. Shin HJ, Ryu JH, Kim ST, Zuo Z, Do SH. Caffeine-induced inhibition of the activity of glutamate transporter type 3 expressed in xenopus oocytes. Toxicol Lett 2013; 217 (2): 143-148.

13. Zeidan-Chulia F, Gelain DP, Kolling EA, Rybarczyk-Filho JL, Ambrosi P, Terra SR, Pires AS, da Rocha JB, Behr GA, Moreira JC. Major components of energy drinks (caffeine, taurine, and guarana) exert cytotoxic effects on human neuronal sh-sy5y cells by decreasing reactive oxygen species production. Oxid Med Cell Longev 2013; 2013: 791-795.

14. Tauler P, Martinez S, Moreno C, Monjo M, Martinez P, Aquilo A. Effects of caffeine on the inflammatory response induced by a $15-\mathrm{km}$ run competition. Med Sci Sports Exerc 2013; 45 (7): 1269-1276.

15. Pohanka M. Role of oxidative stress in infectious diseases. A review. . Folia Microbiol 2013; 58 (6): 503-513.

16. Rodriguez-Naranjo MI, Moya ML, Cantos-Villar E, Garcia-Parrilla MC. Comparative evaluation of the antioxidant activity of melatonin and related indoles. J Food Compos Anal 2012; 28 (1): 16-22.
17. Bordonaba JG, Terry LA. Electrochemical behaviour of polyphenol rich fruit juices using disposable screen-printed carbon electrodes: Towards a rapid sensor for antioxidant capacity and individual antioxidants. Talanta 2012; 90: 38-45.

18. Granot E, Golan D, Rivkin L, Kohen R. Oxidative stress in healthy breast fed versus formula fed infants. Nutr Res 1999; 19 (6): 869-879.

19. Sharma L, Kaur J, Shukla G. Role of oxidative stress and apoptosis in the placental pathology of plasmodium berghei infected mice. PLoS One 2012; 7 (3).

20. Perluigi M, Coccia R, Butterfield DA. 4-hydroxy-2-nonenal, a reactive product of lipid peroxidation, and neurodegenerative diseases: A toxic combination illuminated by redox proteomics studies. Antiox Redox Sign 2012; 17 (11): 1590-1609.

21. Fukui M, Choi HJ, Zhu BT. Rapid generation of mitochondrial superoxide induces mitochondrion-dependent but caspase-independent cell death in hippocampal neuronal cells that morphologically resembles necroptosis. Toxicol Appl Pharmacol 2012; 262 (2): 156-166.

22. Tao LY, Chen XP, Qin ZH, Bian SZ. Could nf-kappa b and caspase-3 be markers for estimation of post-interval of human traumatic brain injury? Forensic SciInt 2006; 162 (1-3): 174-177.

23. Miao EA, Rajan JV, Aderem A. Caspase-1-induced pyroptotic cell death. Immunol Rev 2011; 243: 206-214.

24. Yang B, Ye D, Wang Y. Caspase-3 as a therapeutic target for heart failure. Expert Opin Ther Targets 2013; 17 (3): 255-263.

25. Jaworek J, Leja-Szpak A. Melatonin influences pancreatic cancerogenesis. HIstol Histopathol 2013; in press.

26. Camouse MM, Hanneman KK, Conrad EP, Baron ED. Protective effects of tea polyphenols and caffeine. Expert Rev Anticancer Ther 2005; 5 (6): 1061-1068.

27. Conney AH, Zhou S, Lee MJ, Xie JG, Yang CS, Lou YR, Lu Y. Stimulatory effect of oral administration of tea, coffee or caffeine on uvbinduced apoptosis in the epidermis of skh-1 mice. Toxicol Appl Pharmacol 2007; 224 (3): 209-213.

28. Uney K, Tras B. Comparative pharmacokinetics and metabolisms of caffeine in sheep breeds. J Vet Med Sci 2011; 73 (1): 25-31.

29. Arnaud MJ. Pharmacokinetics and metabolism of natural methylxanthines in animal and man. Handb Exp Pharmacol 2011; 200: 33-91.

30. Petera V, Gross AS, McLachlan AJ. Diurnal variation in cyp1a2 enzyme activity in south asians and europeans. J PHarm Pharmacol 2013; 65 (2): 264-270.

31. Endesfelder S, Zaakl I, Weichelt U, Buhrer C, Schmitz T. Caffeine protects neuronal cells against injury caused by hyperoxia in the immature brain. Free Radic Biol Med 2013; 67C: 221-234.

32. Inkielewicz-Stepniak I, Czarnowski W. Oxidative stress parameters in rats exposed to fluoride and caffeine. Food Chem Toxicol 2010; 48 (6): $1607-1611$.

33. Pohanka M. Cholinesterases, a target of pharmacology and toxicology. Biomed Pap 2011; 155 (3): 219-229.

34. Pohanka M. Alzheimer's disease and related neurodegenerative disorders: Implication and counteracting of melatonin. J Appl Biomed 2011; 9 (4): 185-196.

35. Pohanka M. Alpha7 nicotinic acetylcholine receptor is a target in pharmacology and toxicology. Int J Mol Sci 2012; 13 (2): 2219-2238. 
36. Pohanka M. Acetylcholinesterase inhibitors: A patent review (2008 - present). Expert Opin Ther Pat 2012; 22 (8): 871-886.

37. Pohanka M. Cholinesterases in biorecognition and biosensor construction, a review. Anal Lett 2013; 46 (12): 1849-1868.

38. Krstic D, Knuesel I. Deciphering the mechanism underlying late-onset alzheimer disease. Nat Rev Neurol 2013; 9 (1): 25-34.

39. Tayeb HO, Yang HD, Price BH, Tarazi FI. Pharmacotherapies for alzheimer's disease: Beyond cholinesterase inhibitors. Pharmacol Ther 2012; 134 (1): 8-25.

40. Sultana R, Robinson RA, Lange MB, Fiorini A, Galvan V, Fombonne J, Baker A, Gorostiza O, Zhang J, Cai J, Pierce WM, Bredesen DE, Butterfield DA. Do proteomics analyses provide insights into reduced oxidative stress in the brain of an alzheimer disease transgenic mouse model with an m6311 amyloid precursor protein substitution and thereby the importance of amyloid-beta-resident methionine 35 in alzheimer disease pathogenesis? Antioxid Redox Signal 2012; 17 (11): $1507-1514$

41. Eskelinen MH, Kivipelto M. Caffeine as a protective factor in dementia and alzheimer's disease. J Alzheimer Dis 2010; 20 (S1): 167-174.
42. Chu YF, Chang WH, Black RM, Liu JR, Sompol P, Chen YM, Wei HL, Zhao QY, Cheng IH. Crude caffeine reduces memory impairment and amyloid beta(1-42) levels in an alzheimer's mouse model. Food Chem 2012; 135 (3): 2095-2102.

43. Arendash GW, Cao C. Caffeine and coffee as therapeutics against alzheimer's disease. J Alzheimers Dis 2010; 20 (S1): 117-126.

44. Klein JA, Ackerman SL. Oxidative stress, cell cycle, and neurodegeneration. J Clin Invest 2003; 111 (6): 785-793.

45. Droge W. Free radicals in the physiological control of cell function. Physiol Rev 2002; 82 (1): 47-95.

46. Ghashghaeinia M, Cluitmans JCA, Akel A, Dreischer P, Toulany M, Koberle M, Skabytska Y, Saki M, Biedermann T, Duszenko M, Lang F, Wieder T, Bosman G. The impact of erythrocyte age on eryptosis. Brit J Haematol 2012; 157 (5): 606-614.

47. Swerdlow RH. Alzheimer's disease pathologic cascades: Who comes first, what drives what. Neurotox Res 2012; 22 (3): 182-194.

48. Hwang $\mathrm{O}$. Role of oxidative stress in parkinson's disease. Exp Neurobiol 2013; 22 (1): 11-17. 